\title{
AS TRAMAS DO PODER E SEUS REFLEXOS NO DISCURSO FEMININO DO INÍCIO DO SÉCULO XX EM MARIA DA TEMPESTADE, DE JOÃO MOHANA
}

\author{
MARISTELA DOS SANTOS ALMEIDA ${ }^{1}$ \\ NAIARA SALES ARAÚJO SANTOS ${ }^{2}$
}

\author{
Universidade Federal do Maranhão - UFMA \\ Avenida dos Portugueses, 1966 - Vila Bacanga, São Luís- MA, Cep: 65080-805
}

maristella sa@hotmail.com, naiara.sas2@gmail.com

\begin{abstract}
Resumo. Maria da Tempestade (1956), romance escrito pelo autor maranhense João Mohana, revela o contexto de uma época em que os valores familiares tradicionais eram colocados acima dos ideais de liberdade afetiva e independência. Bárbara, protagonista desta obra literária, mostra-se uma mulher à frente de seu tempo, já que possui anseios e ideais que não condiziam com aqueles atribuídos a uma mulher do início do século XX. Nos anos iniciais deste século, ideais que almejavam conferir mais direitos às mulheres, faziam parte dos discursos em circulação. Diante disto, este artigo tem por objetivo discutir as relações de poder que são estabelecidas entre as principais personagens femininas da obra Maria da Tempestade e como tais relações refletem o discurso patriarcal existente no início do século XX acerca do perfil da mulher na sociedade ludovicense. Para tanto, os estudos de Michel Foucault (2014), bem como alguns conceitos de análise do discurso serão utilizados, a fim de melhor compreender a formação discursiva e a produção de sentidos que estão em circulação no início do século $X X$, periodo em que se passa a narrativa. Para assegurar uma aproximação entre Literatura e Análise do Discurso, mobilizaremos as pesquisas realizadas por Dominique Maingueneau (2016) acerca do Discurso Literário.
\end{abstract}

Palavras-chave: Literatura; Discurso; Poder.

\begin{abstract}
Maria da Tempestade, a novel written by Maranhense author João Mohana, reveals the context of a time when traditional family values were placed above the ideals of affective freedom and independence. Barbara, protagonist of this literary work, shows herself as a woman ahead of her time, since she has longings and ideals that did not match those attributed to a woman of the early twentieth century. In the early years of this century, ideals that sought to give women more rights were part of the speeches in circulation. The purpose of this article is to discuss the relations of power that are established between the main female characters of Maria da
\end{abstract}

\footnotetext{
${ }^{1}$ Mestra em Letras pela Universidade Federal do Maranhão; Professora de Língua Inglesa da rede pública municipal de São Luís - MA.

${ }^{2}$ Docente e Pesquisadora do Mestrado Acadêmico da Universidade Federal do Maranhão.
} 
Tempestade, by the Maranhão writer João Mohana, and how these relations reflect the patriarchal discourse that existed at the beginning of the 20th century about the profile of woman in the Ludovic society. To that end, Michel Foucault's (2014) studies, as well as some concepts of discourse analysis, will be used in order to better understand the discursive formation and the production of meanings that are in circulation at the beginning of the 20th century. narrative. To ensure an approximation between Literature and Discourse Analysis, we will mobilize Dominique Maingueneau's (2016) research on Literary Discourse.

Keywords: Literature. Discourse. Power.

\title{
AS TRAMAS DO PODER E SEUS REFLEXOS NO DISCURSO FEMININO DO INÍCIO DO SÉCULO XX EM MARIA DA TEMPESTADE (1956)
}

Uma questão que permeia a sociedade de uma forma geral são as relações que se estabelecem entre os indivíduos. A partir do Outro, o "eu" passa a se constituir e começam a ser criadas relações, as quais irão ajudar a delimitar a subjetividade do ser. Michel Foucault, que possui uma vasta produção abrangendo várias áreas de estudo, teve como objetivo principal buscar investigar como a vida em sociedade impacta na concepção do homem enquanto ser social.

Em A Ordem do Discurso (1970), ele chama a atenção para o fato de que o discurso é visto como algo perigoso, não porque realmente o seja, mas porque nessa atividade tão quotidiana que é o ato de se expressar, podem estar embutidas relações de poder e problemáticas que os sujeitos sequer imaginam. Quando um sujeito produz um enunciado, este pode vir a desafiar a ordem já estabelecida e aí se instaura o perigo, como diz Foucault:

\begin{abstract}
Suponho que em toda sociedade a produção do discurso é simultaneamente controlada, selecionada, organizada e redistribuída por um certo número de procedimentos que têm por papel exorcizar-lhe os poderes e os perigos, refrear-lhe o acontecimento aleatório, disfarçar a sua pesada, temível materialidade. (FOUCAULT, 2014, p. 8)
\end{abstract}

Diante desse pensamento, é possível inferir que o discurso busca anunciar algo que, a priori, imagina-se como verdade ou como um desejo de verdade e, dessa forma, tal vontade precisa ser partilhada sob a justificativa de que o sujeito realiza uma troca de informação real, verdadeira.

Partindo dessa concepção de Foucault, segundo a qual os discursos poderiam produzir verdades e estas, por sua vez, influenciariam as atitudes dos sujeitos, acredita-se que João Mohana evidenciou a ideia de vontade de verdade atrelada a uma produção de saber. Isso visava a uma coerção, em outras palavras, ao exercício de um poder que controlasse a conduta dos filhos, especialmente das filhas. 


\section{A FORMAÇÃO DISCURSIVA EM MARIA DA TEMPESTADE (1956)}

Empreender a análise de um discurso significa considerar a língua materializada em forma de texto. Assim, a intenção é tornar evidentes os sentidos que ali estão discursivizados por meio da relação que eles estabelecem entre si, como também através das condições sócio-históricas de produção que os tornaram possíveis.

Foucault (2014) compreende o discurso como um conjunto de enunciados que estão vinculados a campos de saber diferenciados, mas que possuem uma regularidade discursiva. Dessa forma, depreende-se que essas regras de funcionamento reproduzem características históricas e linguísticas. Levando em consideração esse pensamento, infere-se que os saberes, as ideologias ou a maneira de pensar que circulam em um determinado período, constituem-se como uma espécie de campo linguístico que permite a existência de enunciados específicos, visando uma produção de sentidos que também é selecionada.

Ao analisar o discurso das personagens Bárbara, Elisa e Cora Mendes, percebeuse que elas foram influenciadas pelos discursos que as circundavam. Essas personagens, cada uma dentro de suas peculiaridades, possuíam marcas do discurso patriarcal e autoritário que era vigente no período em que se desenvolveu a narrativa.

Pêcheux (1975) entende "não haver discurso sem sujeito e nem sujeito sem ideologia". Dito isso, tem-se as personagens de Elisa e Godofredo, que em seus discursos veiculam ideias autoritárias e patriarcais. Para essas personagens, os filhos deveriam acatar aquilo que era determinado pelos pais. Quando um dos filhos decide casar-se com uma moça diferente da que eles haviam planejado, um embate acontece na família:

- Você ficou maluco, menino? Era essa a pergunta inesperada, mas sempre indefectível, toda vez que qualquer um de nós punha a própria vontade em ação. Não compreendiam que agíssemos uma só vez por nossa cabeça. Teríamos sempre de executar nunca deliberar. E cada tentativa de sermos nós mesmos era alcunhada de maluquice, doidice de menino. (MOHANA, 2016, p. 34)

Levando em consideração a organização de um discurso e também a sua ordenação, é preciso lembrar que ele possui um sentido, cuja origem se faz presente nas escolhas feitas pelo locutor, a fim de comunicar algo. Partindo dessa premissa, entendese que os enunciados dos pais de Bárbara possuíam uma intenção: persuadir a filha a aceitar as ideias que ambos tinham a respeito da conduta de uma mulher naquela época.

Beauvoir (2016) ressalta que a mulher vivia à sombra dos homens, sem direito de expressar sua opinião e destinada a executar aquilo que eles haviam pensado ou escolhido para elas. Segundo a autora, a mulher era "condenada a desempenhar o papel do Outro, a mulher estava condenada também a possuir apenas uma força precária: escrava ou ídolo, nunca é ela que escolhe o seu destino. O lugar da mulher na sociedade é sempre escolhido por eles" (BEAUVOIR, 2016, p. 112).

Em relação à constatação feita por Beauvoir, Mohana traz para a narrativa de Maria da Tempestade (1956) uma protagonista que, em vários momentos, questiona o 
comportamento e as regras às quais é submetida e sente-se revoltada com os pais por estes insistirem em escolher o seu destino. Após a festa de casamento de um de seus irmãos, Bárbara questiona a ideia dos pais sobre a instituição do casamento:

Mamãe e papai podiam considerar tolice um casamento, a ponto de bastar ter boa fortuna um sujeito para se tornar um "bom partido", como se fortuna pudesse substituir o amor de um coração fiel. Se eles, Tia Zulmira, Tio Mundinho (etc) pensavam assim, minha opinião era inteiramente diversa. (MOHANA, 2016, p. 54)

Para cada uma das personagens centrais de Maria da Tempestade (1956), foi possível visualizar uma formação ideológica diferente, que por sua vez proporcionou uma produção de discursos diferenciados, revelando, assim, que elas faziam parte de uma determinada época e momento histórico que viabilizaram a produção desses discursos. Foucault (1995) entende tal prática como formação discursiva (FD) e sobre isso afirma que:

No caso em que se puder descrever, entre um certo número de enunciados, semelhante sistema de dispersão, e no caso em que entre os objetos, os tipos de enunciação, os conceitos, as escolhas temáticas, se puder definir uma regularidade (uma ordem, correlações, posições e funcionamentos, transformações), diremos, por convenção, que se trata de uma formação discursiva. (FOUCAULT, 1995, p. 43)

Depreende-se, então, que uma formação discursiva possui relação com processos históricos que ajudam na constituição dos discursos. É mediante os acontecimentos e regras que fazem parte de uma sociedade e de um determinado momento histórico que enunciados específicos passam a emergir e a veicular uma forma de pensar específica que também intenta propagar os saberes e ideias de uma época ou grupo de pessoas.

De acordo com esse entendimento, evidenciou-se que as personagens Bárbara, Elisa e Cora Mendes faziam parte de um momento histórico que concebia a mulher como alguém que ainda deveria seguir regras rígidas de comportamento, além de dever obediência aos pais e observar atentamente os padrões de comportamento da sociedade. Conforme Constância Duarte (2003):

(...) as mulheres brasileiras, em sua grande maioria, viviam enclausuradas em antigos preconceitos e imersas em uma rígida indigência cultural (...). A primeira legislação autorizando a abertura de escolas públicas data de 1827 , e até então as opções eram uns poucos conventos, que guardavam as meninas para o casamento, raras escolas particulares na casa das professoras, ou o ensino individualizado, todos se ocupando apenas com as prendas domésticas. (DUARTE, 2003, p. 152)

Concebe-se que esses padrões de comportamentos, bem como as normas, os objetos, os enunciados e as opiniões, obedecem a regras de formação que refletem as circunstâncias de existência em uma formação discursiva. 
No tocante à formação discursiva - à luz dos estudos foucaultianos -, entende-se que tal procedimento constitui-se de uma regularidade de correlações, posições, funcionamentos e transformações entre objetos; também os seus enunciados, as escolhas temáticas e os conceitos envolvidos em um certo número de enunciados presentes em um sistema de dispersão, ou seja, a formação discursiva em Foucault é um conjunto de enunciados que foram possíveis a partir de uma conjuntura externa que autoriza ou restringe a produção de determinados enunciados, os quais apenas possuem determinado momento para serem constituídos e também para significarem da maneira esperada.

\section{RELAÇÕES DE PODER E O DISCURSO DAS PERSONAGENS BÁRBARA, ELISA E CORA MENDES}

Na narrativa de Maria da Tempestade (1956) foram identificadas relações estabelecidas entre Bárbara e sua mãe, Elisa, bem como com a senhora Cora Mendes. Tais conexões produziram, em algumas ocasiões, situações de tensão que foram responsáveis por momentos de enfrentamento durante a narrativa. $\mathrm{O}$ discurso de Elisa, mãe de Bárbara, configurou-se como um discurso autoritário no qual a obediência era compulsória, caso contrário, as consequências eram punições severas.

Outro discurso que acompanha a protagonista em momentos relevantes da obra é o da senhora Cora Mendes, que se estabelece como um discurso decadente de uma mulher que seguiu os preceitos da sociedade de sua época, mas que nos anos avançados de sua vida se encontrava abandonada e mergulhada em seu vício por morfina, para assim esquecer a vida sem perspectivas que passou a ter em São Luís.

Por outro lado, o discurso da protagonista mostra uma visão diferenciada para uma mulher que vivia nos anos iniciais do século XX. Simplesmente, Bárbara não se encaixava nos padrões criados pela sociedade de seu tempo para a vida de uma mulher, uma vez que enxergava perspectivas novas e acreditava na possibilidade de viver sob um ângulo diferente, segundo o qual ela podia fazer suas próprias escolhas. Assim, ela não compreendia como aceitável que seus pais, principalmente a sua mãe, interferissem em suas decisões.

Isto posto, passar-se-á à análise dos discursos dessas personagens no intuito de investigar as marcas do discurso patriarcalista, bem como evidenciar as transformações em fluxo no discurso feminino a partir da personagem Bárbara e sua trajetória dentro da obra.

\section{O DISCURSO DE ELISA}

No início do século XX, a sociedade maranhense, assim como boa parte da sociedade brasileira, vivia sob os ditames do patriarcalismo, do autoritarismo familiar e também dos preceitos religiosos. Nesse contexto, os pais de Bárbara, sobretudo sua mãe Elisa, eram marcados pela maneira de pensar daquela sociedade, que conduziu à produção de enunciados extremamente machistas e autoritários.

Ao se depararem em situação de convívio, dois grupos tentarão estabelecer seu domínio e "quando duas categorias estão em estado de sustentar a reivindicação, cria-se 
entre elas uma reciprocidade. Se uma das duas é privilegiada, ela domina a outra e tudo faz para mantê-la na opressão" (BEAUVOIR, 2016, p. 95). A personagem Elisa tenta impor sua vontade sobre a filha e tudo faz para dominar o instinto questionador da jovem. Dessa forma, o discurso da mãe se reveste de marcas ideológicas que sustentam sua soberania e a fazem exercer seu poder de progenitora.

Nessa lógica e com o intuito de ser ouvida, Elisa utiliza a disciplina severa com os filhos. Sendo a filha aquela que mais contesta a maneira como a mãe conduz sua relação com os filhos, é sobre Bárbara que o peso da relação de dominação e poder se impõe de maneira mais evidente. O exercício dessa autoridade se revela na disciplina, na imposição de penas: "'Se fizeres isso outra vez, tu apanhas'. O medo da surra peava meus movimentos inocentes, amortecia meus sonhos tão simples, meus sentimentos mais puros que amanheciam para a vida" (MOHANA, 2016, p. 12).

Em Vigiar e Punir, Foucault (2014) investigou o sistema das prisões e seus efeitos disciplinadores sobre os encarcerados. Para o filósofo, a disciplina do corpo trazia consequências positivas no sentido pretendido: a punição e o castigo físicos exerciam controle sobre aqueles que sofriam com as penas. A dor podia ser sentida tanto por quem a vivia de fato, como também pelos espectadores, logo, era uma maneira eficaz de se obter disciplina e admoestação, pois, segundo o autor, "o corpo só se torna força útil se é ao mesmo tempo corpo produtivo e corpo submisso. Essa sujeição não é obtida só pelos instrumentos da violência ou da ideologia; pode muito bem ser direta, física, usar a força contra a força..." (FOUCAULT, 2014, p. 29), ou seja: os seus efeitos de dominação eram alcançados.

Nessa perspectiva, Elisa fez uso de estratégias de dominação para conseguir a obediência dos filhos, uma vez que era autorizada por seu lugar de mãe. Por consequência, ela investiu sobre os filhos e o marido - a partir de uma relação de poder e saber -, submetendo-os e fazendo deles objetos de saber (FOUCAULT, 2014). Em síntese, a personagem em questão era uma mulher com personalidade forte, que tratava os filhos com autoridade e exercia poder sobre eles através da disciplina do corpo:

(...) - Desça da janela. Assanhada. Soube que está se encontrando com um sujeito que não vale nada, é verdade?

- É verdade que estou me encontrando com um rapaz, mas não é verdade que ele não valha nada.

- Cale-se, atrevida.

- A senhora não me perguntou?

- Perguntei. Mas isso é resposta que uma filha dê à mãe?

- E isso é nome que uma mãe chame à filha?

- Quando a filha merece, é.

- Mesmo que mereça, isso é modo de uma mãe dizer o que a filha merece?

Avançou em cima de mim, e, dando-me na cara, furou com a voz meu tímpano:

- Sua atrevida, quer me dar lição? Saiba que esse namoro tem de acabar e você não sairá mais a parte alguma. (MOHANA, 2016, p. 83)

Uma vez inserida na formação discursiva do início do século XX - apresentada anteriormente -, ficou notório que a personagem reproduziu um discurso impositivo e 
patriarcalista em relação à filha, além de estabelecer relações de poder para com a jovem Bárbara, pois Elisa acreditava que "as mulheres pertencem à família e não à sociedade política, e a natureza as fez para as atividades domésticas e não para as funções públicas" (BONALD, apud BEAUVOIR, 2016, p. 161).

Já que Elisa ocupava a posição de mãe, ela era naturalmente investida de poder sobre seus filhos, principalmente sobre a filha, pois esta era "mulher". Fica evidente que os meios utilizados por Elisa visavam coagir a filha a fazer aquilo que ela desejava. Foucault (2014) comenta sobre isso dizendo que:

(...) o estudo desta microfísica supõe que o poder nela exercido não seja concebido como uma propriedade, mas como uma estratégia, que seus efeitos de dominação não sejam atribuídos a uma "apropriação", mas a disposições, a manobras, a táticas, a técnicas, a funcionamentos; que se desvende nele antes uma rede de relações sempre tensas, sempre em atividade, que um privilégio que pudesse se deter (...) esse poder se exerce mais que se possui. (FOUCAULT, 2014, p. 30)

Consoante Foucault, tem-se que os enunciados da personagem Elisa tencionavam coagir Bárbara diante do comportamento contestador da jovem em relação à sua vida sentimental. Através daquilo que a mãe impôs à Bárbara, o resultado esperado era que a filha desistisse de continuar o relacionamento que vinha mantendo com Guilherme, rapaz por quem se apaixonou, mas com o qual não pode continuar se relacionando por imposição dos pais.

A partir desses eventos, entende-se que Elisa estava inserida em uma formação discursiva que proporcionou a produção de um discurso patriarcalista e ditador sobre a figura da mulher. A personagem, então, enquadra-se como produto de relações de poder que são exercidas sobre o sujeito. Em seu caso, as convivências sociais às quais foi submetida ajudaram a compor um sujeito atravessado e afetado por seus arredores sociais, influenciando a sua constituição subjetiva.

\section{O DISCURSO DE CORA MENDES}

Outro discurso que surge em Maria da Tempestade (1956) é o da personagem Cora Mendes, senhora que teve uma vida glamorosa na juventude e da qual não conseguia se despedir. Cora Mendes residia em uma casa que refletia o estado de abandono em que ela própria vivia e no qual estava mergulhada. Todas as noites, ao fazer uso de uma droga para dormir, a pobre senhora embarcava em sua viagem de volta ao passado alegre e feliz que havia tido, onde viveu os melhores anos de sua vida enquanto era casada com um homem de posses.

A personagem Cora Mendes estava enquadrada na categoria que Simone de Beauvoir chama de "mulheres burguesas", que segundo a autora - em razão da educação que receberam - foram "colocadas sob a dependência do homem, não ousam sequer apresentar reivindicações" (BEAUVOIR, 2016, p. 163). Após o falecimento do marido, Cora Mendes começa a enfrentar as dificuldades da vida construída em torno da figura do esposo. Ela havia passado os anos do casamento vivendo à sombra do companheiro e, dessa forma, aceitou a condição que era oferecida às mulheres de seu tempo: contentou- 
se com os luxos que recebia e aprendeu a ser a esposa que não questiona as atitudes do marido.

Cora Mendes estava inserida no discurso patriarcalista e autoritário da sociedade do século XIX e na sua velhice vivia as transformações que estavam acontecendo no discurso dos anos iniciais do século XX:

Quando se diz homem, quer dizer-se homem e mulher. Isso é humilhante para nós, mas paciência, é costume, acabou-se. Pois bem, ele dizia: "Cora, o homem deve ser como Deus. Deve ter sempre uma pontinha de mistério. É a única maneira de conseguir ser lembrado, de usufruir um pouco da atenção alheia. O mistério é o sal do convívio humano" (...).

- O que era para a senhora?

- Amante, minha filha. Amante. Homem maravilhoso. Tocava Beethoven como ninguém.

- E onde se conheceram?

- Em Paris. Já não disse que foi em Paris? (...) se engraçou de mim, me engracei dele (...). (MOHANA, 2016, p. 167-168)

Foucault (2014) considera a produção do discurso controlada, organizada, selecionada e redistribuída através de alguns tipos de procedimentos que visam atribuir poderes e perigos, dominar certos processos e deixar de lado certas materialidades discursivas que podem se apresentar como desafiadoras. Em seu momento decadente, Cora Mendes passou a ser vista como uma espécie de bruxa, de velha esquisita, sem família, sem posses e cujo discurso assemelhava-se ao dos loucos. Colocada nessa equiparação com alguém cujas faculdades mentais são falhas, ela sofria o impacto de procedimentos de exclusão, a saber, o da rejeição, já que era "através de suas palavras que se reconhecia a loucura do louco" (FOUCAULT, 2014, p. 11).

Nessa perspectiva, Cora Mendes sofria os efeitos de três processos de interdição, a saber, o fato de ser mulher, o de ser considerada "louca" e o de ser economicamente falida. Com esse cenário ao seu redor, a senhora passou a viver à margem da sociedade, temida por alguns, desprezada por outros e explorada por outra parte:

Essa resposta era o atestado de isolamento em que vivia aquela criatura. Não vivia em São Luís. Vivia em sua casa, e nada mais. Não saía a parte alguma, nem recebia visitas de ninguém, a não ser dos ladrões (...). Fiquei surpreendida ao ver a espontaneidade dela, a comunicabilidade, pois a ideia que fazia era de ser uma criatura fechada, doentia e má. (MOHANA, 2016, p. 139-140)

No fragmento anterior foi possível perceber que Cora Mendes era, de fato, uma pessoa que vivia em um mundo à parte e experimentava a solidão à qual foi conduzida em razão de suas escolhas. Vivendo em um mundo que misturava realidade e ilusão, Cora Mendes recebeu Bárbara em sua casa e assim começaram a ter mais proximidade, o que mais tarde vai gerar alguns momentos de conflito entre ambas.

Ao descobrir que o vício da senhora havia ceifado a vida de sua filha, Bárbara passa por um momento de revolta e decide acabar com a dependência da idosa: "Tratei de fazer tudo para livrá-la do vício. Era um bem que eu faria a ela e a mim mesma" 
(MOHANA, 2016, p. 264). A jovem decide trancar a idosa em um quarto e privá-la do uso de morfina para que assim a dependência pudesse acabar.

Eu sabia de um caso, parente do F... até, que deixara o vício porque a amante prendera-o durante uma semana no quarto, sem fumar morfina. Era o que eu ia fazer com Cora Mendes. (...) Parecia evidente que para consertar o mundo desmantelado ali naquele ponto (...). Ponderei os prós e os contras e iniciei os trabalhos. Nada de discussões, nada de argumentos. Ação. Pedi a seu Antônio, o verdureiro, que me comprasse duas argolas grossas, resistentes. (...) Comprou. Trouxe (...). Colocou as argolas na porta do quarto $\mathrm{n}^{\circ} 1$. Experimentamos o cadeado, ficou esplêndido. Firme à vontade, dando ampla margem de tranquilidade durante as noites. Deixamos entre as duas folhas uma fenda estreita, por onde eu pudesse olhar e atendê-la nas necessidades. Estava desse modo pronta a gaiola de ferro. À espera do pássaro de fogo. (MOHANA, 2016, p. 267)

Nesse momento da narrativa, a protagonista lançou mão da disciplina sobre o corpo de Cora Mendes, impondo à senhora a suspensão, de forma compulsória, do vício. Bárbara impôs domínio sobre o corpo de uma outra pessoa, não apenas para que a idosa fizesse aquilo que ela queria, mas para que ela passasse a agir como Bárbara esperava: de forma rápida e eficaz. (FOUCAULT, 2014)

O corpo de Cora Mendes é, dessa forma, esquadrinhado, desarticulado e recomposto (FOUCAULT, 2014) e depois de um tempo passa a operar da maneira que foi articulado pela jovem. No entanto, durante o processo de controle e domesticação desse corpo, ambas impõem resistência e estabelecem "relações de poder que têm por base, essencialmente, uma relação de força" (FOUCAULT, 2017, p. 275). Bárbara, mesmo ferida pela perda da filha, encontra força e decide castigar Cora Mendes de outra maneira.

Bárbara não é detentora de um poder legal para aprisionar alguém em um local pelo tempo que acha necessário, no entanto, ela exerce esse poder porque na relação estabelecida com Cora Mendes, quem detém o poder, nesse momento, é a jovem, que o exerce plenamente, constatando-se, assim, que "o poder é essencialmente repressivo. O poder é o que reprime a natureza, os indivíduos, os instintos, uma classe" (FOUCAULT, 2017 , p. 274), isto é, por meio do exercício de um poder, o indivíduo é afetado e atravessado por forças que o moldam. Esse exercício de poder que tem a capacidade de transformar comportamentos e também de estabelecer relações de força será observado no comportamento da jovem Bárbara, objeto de análise presente no subtópico a seguir.

\section{O DISCURSO DE BÁRBARA}

Bárbara Sena foi uma jovem que viveu em São Luís e narra os acontecimentos imprevisíveis que aconteceram em sua vida entre os anos de 1907 e 1917. Ela é a única mulher de seis filhos e possuía uma ama de companhia que a ajudava com todas as suas atividades escolares e também com as obrigações que eram próprias para as mulheres do início do século XX na sociedade. 
A personagem almejava uma vida livre, em que ela pudesse fazer suas escolhas, principalmente no que diz respeito à sua vida sentimental. Sua maneira de pensar refletia alguns acontecimentos da sociedade que naquele momento presenciava:

(...) modificações também na estrutura da família brasileira, reforçando ideais burgueses da família, do casamento e do papel da mulher na sociedade. A condição feminina foi, lentamente, sendo modificada desde os fins do século XIX, com maior participação no mercado de trabalho, reivindicações feministas que ao redor do mundo alertavam várias mulheres acerca das desigualdades de direitos, mesmo levando em consideração que o papel feminino na sociedade se manteve praticamente estável. (SALES, 2015, p. 615)

Com base nessas evidências, depreende-se que o discurso da protagonista possui semelhança com o discurso feminino em ascensão nos anos iniciais do século XX. Esse modo de pensar que entende as mulheres como detentoras de capacidade intelectual, com liberdade de decisão e competência para ocupar postos de trabalhos semelhante aos dos homens, passou a ser enfatizado nesse período e encontrou eco na personagem Bárbara.

Diante disso, infere-se também que Bárbara não aceitava como verdade o discurso patriarcalista que fazia crer que uma mulher não detinha capacidade para fazer escolhas concernentes à sua vida. Foucault (2017) compreende que:

(...) o poder em seu exercício vai muito mais longe, passa por canais muito mais sutis, é muito mais ambíguo, porque cada um de nós é, no fundo, titular de um poder e, por isso, veicula poder. O poder não tem por função única reproduzir as relações de produção. As redes da dominação e os circuitos da exploração se recobrem, se apoiam e interferem uns nos outros, mas não coincidem. (FOUCAULT, 2017, p. 255)

Considerando-se essa afirmação de Foucault, entende-se que Bárbara, apesar de sentir os efeitos do poder autoritário dos pais, também se constituía como alguém que veiculava poder, já que ao se posicionar de forma oposta à vontade dos pais, exercia força, resistência e produzia situações de tensão dentro do seu ambiente familiar, já que, "o poder é algo que circula, que só funciona em cadeia" (FOUCAULT, 2017, p. 284). Nesse âmbito, a protagonista compreendia que ao se posicionar contra as vontades dos pais, estaria impondo sua maneira de pensar e poderia ter como reação uma possível mudança de opinião a partir de sua decisão de enfrentá-los:

Não. Não queria Tio Afonso. Poderia encher-me de dinheiro, de jóias, de sedas. Por trás disso tudo estaria um coração de mulher sempre insatisfeito por não ser amado e um coração de filha sempre triste por ter traído os projetos do Pai a seu respeito. Sabia que iria ter muita briga, muita discussão, muita desavença, mas estava disposta a enfrentar tudo. (MOHANA, 2016, p. 65)

Embora vivesse em uma sociedade patriarcal, autoritária e fosse muito mais cerceada em sua liberdade do que seus irmãos, Bárbara foi a que mais demonstrou força e por isso veiculou poder: 
Guilherme é o nome de minha vida, o nome do homem que amei. (...) "Pobre", como dizia Tia Zulmira, ou "baixo", como dizia mamãe, ou "vergonhoso", como dizia papai, ou "traste", como dizia Tio Afonso, foi minha honra, meu ideal de mulher (...). Tive o privilégio máximo que uma mulher pode ter. Indo de encontro a tudo e a todos... (MOHANA, 2016, p. 64)

Ao enfrentar a família e a sociedade para ter o direito de escolher e permanecer ao lado daquele que ela havia decidido se casar, Bárbara novamente demonstrou estar imersa no discurso feminino que ganhava força no início do século XX, sendo conhecido como movimento feminista e entendido como "todo gesto ou ação que resulte em protesto contra a opressão e discriminação contra a mulher ou que exija a ampliação de seus direitos, seja por iniciativa individual ou de grupo" (DUARTE, 2003, p. 2).

Diante disso, a personagem em questão fazia parte de um âmbito social que estava em transição em sua maneira de enxergar a mulher. De acordo com esse pensamento ainda vigente nos anos em que a narrativa de Maria da Tempestade (1956) se desenrola, na figura da mulher estava "a solidez da família, a garantia da propriedade privada: exigiase a presença da mulher no lar tanto mais vigorosamente quanto sua emancipação tornavase uma verdadeira ameaça” (BEAUVOIR, 2016, p. 20).

O discurso patriarcal entendia que a mulher "não é senão o que o homem decide que seja" (BEAUVOIR, 2016, p. 12), isto é, que era desprovida da capacidade de comandar e decidir a própria vida, requerendo para isso a ajuda do homem ou dos pais. Além disso, ela tinha o seu discurso interditado por não satisfazer às condições de funcionamento que eram a ele intrínsecas, pois "ninguém entrará na ordem do discurso se não satisfizer a certas exigências ou se não for, de início, qualificado para fazê-lo" (FOUCAULT, 2014, p. 35).

Conforme acompanhou-se durante os desdobramentos da narrativa de Maria da Tempestade (1956), a personagem Bárbara tinha o seu discurso interditado, já que não se enquadrava nos requisitos exigidos pela sociedade de sua época. Um deles era o fato de ser mulher, o outro era o pensamento diferenciado que a jovem possuía em relação aos ideais autoritários que enfrentava. Dessa forma, Bárbara reveste-se de força para enfrentar as situações que especialmente sua família lhe impôs.

Nesse sentido, Bárbara passou a se fortalecer em suas convicções e, assim, tornouse um efeito do poder que era exercido sobre ela, além de simultaneamente exercer poder para se manter na ordem do discurso. A jovem exercia seu poder em rede e sofria as consequências dele (FOUCAULT, 2017). Dessa maneira, Bárbara mantinha-se forte: "Digo-te com sinceridade: estou disposta a fazer meu destino. Conto para isso com a ajuda de Deus. Se meus pais e a sociedade se atravessarem no meio, tomarão uma lição de nós três: de mim, de Guilherme e de Deus" (MOHANA, 2016, p. 78).

Por isso, a personagem Bárbara, ao estar inserida nas tramas do poder, tornou-se aquilo que o poder veiculado pelos atores sociais fizeram dela: uma mulher forte, com poucos momentos de fragilidade, com a certeza de que precisava resistir e estabelecer os alicerces que a ajudariam a produzir ou propagar o novo discurso feminino que brotava no início do século XX e que trouxe novas compreensões sobre o papel da mulher na sociedade. 


\section{CONSIDERAÇÕES FINAIS}

Esta análise teve como orientação alguns princípios da Análise do Discurso, algumas contribuições de Michel Foucault sobre a organização dos discursos e os dispositivos de poder, além dos estudos realizados por Dominique Maingueneau sobre o discurso literário. Além disso, permitiu mostrar como os saberes instituídos criam relações de poder e como isso influenciou e construiu a personagem Bárbara, na obra Maria da Tempestade (1956) do escritor maranhense, Padre João Mohana.

Às mulheres que viveram no início do século XX eram atribuídas funções e obrigações que foram cristalizadas a partir de discursos machistas e autoritários que vinculavam a mulher aos afazeres domésticos, à criação dos filhos, aos cuidados com a casa, ao cumprimento de obrigações religiosas e à sua vida sentimental, ou seja, o marido escolhido pelos pais.

Através da análise empreendida, foi possível perceber as relações interpessoais estabelecidas em uma sociedade e como elas instituem lugares de poder no convívio entre os sujeitos. Na obra analisada, os enunciados das personagens estão marcados por vontades de verdade que irão caracterizar os sujeitos envolvidos, bem como os enunciados utilizados por esses sujeitos, o que traz à tona situações de tensão onde o poder se encontra fluido.

Portanto, percebeu-se que as personagens Bárbara, protagonista da obra Maria da Tempestade (1956), bem como Elisa e Cora Mendes, desenvolvem um vínculo de influência entre si. O poder que essas três mulheres veiculam durante a narrativa está diluído em seus modos de agir e, além do mais, de maneira sutil, tal poder influencia na constituição de suas personalidades, que passam a ser atingidas pelos efeitos de tensão de suas relações.

Acredita-se que foi possível gerar uma reflexão sobre os discursos que circulavam no Brasil - mais notadamente em São Luís, entre os anos de 1907 e 1917 - e sobre a maneira como eles circundavam a sociedade apresentada durante a narrativa. Dessa forma, percebeu-se que os discursos se constituem como práticas que caracterizam os sujeitos e as formações discursivas das quais eles fazem parte, influenciando a produção de sentidos e instaurando lugares de poder dentro das relações entre sujeitos.

Assim, verificou-se um fértil campo de estudo nas interfaces entre Literatura e Discurso, ampliando ainda mais as possibilidades de pesquisas no universo da Análise do Discurso Literário. Por fim, espera-se que o estudo realizado possa oferecer caminhos e possibilidades de investigação para novas pesquisas, permitindo que a literatura maranhense alcance maior visibilidade e ganhe oportunidades de leitura e análise em futuras abordagens.

\section{REFERÊNCIAS}

ABRANTES, Elizabeth Sousa. De Normalistas a Doutoras: a trajetória feminina de acesso ao ensino superior no Maranhão Republicano. In: Histórias do Maranhão em tempos de República. NERIS, Wheriston Silva et al (orgs.). São Luís: EDUFMA, 2015. 
BAKHTIN, Mikhail. Questões de Literatura e de estética (a teoria do romance). 3 ed. São Paulo: Ed. UNESP, 1993.

BEAUVOIR, Simone de. O Segundo Sexo. São Paulo: Nova Fronteira, 2016.

BRANCO, Lúcia Castello. O que é escrita feminina. São Paulo: Editora Brasiliense, 1991.

BRANDAO, Jacyntho Jose Lins. Presença maranhense na literatura nacional. São Luís: UFMA; SIOGE, 1976.

CANTELE, Bruna R. História Dinâmica do Brasil. São Paulo: IBEP, 1996.

CHIZOOTTI, Antonio. Pesquisas em ciências humanas e sociais. São Paulo: Cortez, 1995.

CORREIA, Janaína Santos. Maria Firmina dos Reis, vida e obra: uma Contribuição para a Escrita da História das Mulheres e dos Afrodescendentes no Brasil. Revista Feminismos. V. 1, $\mathrm{n}^{\mathrm{o}}$ 3. São Paulo: set/dez 2013. Disponível: $<$ http://www.feminismos.neim.ufba.br/index.php/revista/article/view/27/71>. Acesso em: 09 abr. 2018.

DA SILVA, Régia Agostinho. O texto no feminino: a literatura feita por mulheres no Ceará no fim do século XIX e início do XX. In: Letras e Veredas da História: diálogos e convergências. AGOSTINHO, Régia; BACCEGA, Marcus (orgs.). São Luís: EDUFMA, 2018.

DE MELLO, Renato. Análise do Discurso e Literatura: uma interface real. In: Análise do Discurso e Literatura. DE MELLO, Renato (org.). Belo Horizonte: Núcleo de Análise do Discurso, Programa de Pós-Graduação em Estudos Linguísticos, Faculdade de Letras da UFMG, 2005.

DEL PRIORE, Mary (org.). História das mulheres no Brasil. 5. ed. São Paulo: Contexto, 2001.

DUARTE, Constância Lima. Feminismo e literatura no Brasil. Estudos Avançados. vol. 17, $\mathrm{n}^{\mathrm{o}}$ 49. São Paulo: set/dez. 2003. Disponível em: $\leq$ http://www.scielo.br/scielo.php?script=sci_arttext\&pid=S0103-40142003000300010 $>$. Acesso em: 05 abr. 2018.

GALIANARI, Melliandro Mendes. A autoralidade do discurso literário. In: Análise do Discurso e Literatura. DE MELLO, Renato (org.). Belo Horizonte: Núcleo de Análise do Discurso, Programa de Pós-Graduação em Estudos Linguísticos, Faculdade de Letras da UFMG, 2005.

GIL, Antonio Carlos. Métodos e técnicas de pesquisa social. São Paulo: Atlas, 2014.

GRONDIN, Jean. Hermenêutica. São Paulo: Parábola Editorial, 2012.

FERNANDES, Cleudemar. Análise do discurso: reflexões introdutórias. São Carlos: Claraluz, 2007.

FERREIRA, Antonio Celso. A fonte fecunda. In: PINSKY, Carla Bossanezi; LUCA, Tania Regina de (orgs.). O historiador e suas fontes. São Paulo: Editora Contexto, 2009. FONSECA, Mário Alves da. Michel Foucault e a constituição do sujeito. São Paulo: EDUC, 2003.

FOUCAULT, Michel. A ordem do discurso. Tradução de Laura Fraga de Almeida Sampaio. 24. ed. São Paulo: Edições Loyola, 2014.

História da Sexualidade: a vontade de saber. Tradução de Maria Thereza da Costa Albuquerque e J. A. Guilhon Albuquerque. Rio de Janeiro: Edições Graal, 1988.

Microfísica do Poder. Organização, introdução e revisão técnica de Roberto Machado. 6. ed. Rio de Janeiro/São Paulo: Paz e Terra, 2017. 
Vigiar e Punir: nascimento da prisão. Tradução de Raquel Ramalhete. 42. ed. Petrópolis, Rio de Janeiro: Vozes, 2014.

LEAO, Ricardo. Os atenienses e a invenção do cânone nacional. 2. ed: São Luís: Instituto GEIA, 2013.

MAINGUENEAU, Dominique. Discurso Literário. Tradução de Adail Sobral. 2. ed. São Paulo: Contexto, 2016.

MOHANA, João. Maria da Tempestade (1956). 9. ed. São Luís: Edições AML, 2016. Plenitude humana. Porto Alegre: Globo, 1977.

MORAES, Jomar. Perfis acadêmicos; pesq. e textos. 3. ed. São Luís: 1993.

NISKIER, Arnaldo. O Olhar Pedagógico em Machado de Assis. Rio de Janeiro: Expressão e Cultura, 2001.

ORLANDI, Eni P. Análise de discurso: princípios e procedimentos. 10. ed. Campinas, SP: Pontes Editores, 2012.

SALES Tatiane da Silva. Pedagogia da diferenciação entre Meninos e Meninas em São Luís na Primeira República. In: Histórias do Maranhão em tempos de República. NERIS, Wheriston Silva et al (orgs.). São Luís: EDUFMA, 2015.

VASCONCELOS, Sandra Guardini Teixiera. Construções do feminino no romance inglês do século XVIII. Revista Polifonia, v. 2, p. 85-100. Cuiabá: EDUFMT, 1995.

WOOLF, Virgínia. Um teto todo seu. Tradução de Vera Ribeiro. São Paulo: Nova Fronteira, 1994.

Artigo recebido em: set. de 2019.

Aprovado e revisado em: mar. de 2020.

Publicado em: julho de 2020.

Para citar este texto:

ALMEIDA, Maristela dos Santos; SANTOS, Naiara Sales de Araújo. As Tramas do Poder e seus Reflexos no Discurso Feminino do Início do Século XX em Maria da Tempestade, de João Mohana. Entremeios [Revista de Estudos do Discurso, ISSN 2179-3514, on-line, www.entremeios.inf.br], Seção Estudos, Programa de Pós-Graduação em Ciências da Linguagem (PPGCL), Universidade do Vale do Sapucaí (UNIVÁS), Pouso Alegre (MG), vol. 21, p. 53-66, jan. - jun. 2020.

DOI: http://dx.doi.org/10.20337/ISSN2179-3514revistaENTREMEIOSvol21pagina53a66 